\title{
The persistence of social attraction in socially deprived and satiated rats
}

\author{
BIBB LATANÉ \\ Ohio State University, Columbus, Ohio 43210 \\ and \\ CLAUDE STEELE \\ University of Washington, Seattle, Washington 98105
}

\begin{abstract}
Pairs of socially deprived or satiated rats were observed for $7 \frac{1}{2}$ continuous hours in an open field. Social contact increased monotonically throughout this time, with socially deprived animals showing more attraction, and a greater increase in attraction, than satiated animals. The quality of social contact changed, however, from a predominantly active interaction, in which the most sociable animals were most mobile, to a predominantly passive huddling, in which the most sociable animals were least mobile. The results suggest that social attraction in rats is not transitory, and may serve several different functions.
\end{abstract}

A number of studies in recent years have explored the determinants of social attraction in pairs of rats allowed to move freely in a circular open field (e.g., Latané, 1969; Latané \& Glass, 1968; Latané, Joy, Meltzer, Lubell, \& Cappell, 1972; Latané \& Werner, 1971; Joy \& Latané, 1971). These studies have found rats to be very sociable, spending up to two-thirds of their time in direct physical contact, chasing each other around, sniffing at and rubbing up against each other, and crawling over and under each other. With continued exposure to the open field, rats become more sociable, presumably as competing tendencies to explore the field itself drop out (Eckman, Meltzer, \& Latané, 1969; Latané \& Walton, 1972).

Many of these studies have also found that rats housed in social isolation and deprived of the opportunity for social interaction are more affiliative than rats housed in continuous social contact, and show a greater increase in affiliation with continued exposure to the open field (Cappell \& Latané, 1969; Latané, Cappell, \& Joy, 1970; Latané, Nesbitt, Eckman, \& Rodin, 1972; Latané, Schneider, Waring, \& Zweigenhaft, 1971; Latané, Poor, \& Sloan, 1972; Latané \& Walton, 1972; Walton \& Latané, 1972).

In each of the two dozen experiments reported in the above papers, pairs of rats were observed over a number of daily 5-min observation periods. Five minutes is not a very long time (only about one-third of $1 \%$ of a day), and it may be that this arbitrary choice of observation period has led to misleading findings. For example, it is possible that rats really have only the most fleeting interest in each other, and that if we were to observe them over longer time spans, we would discover them to be relatively uninterested in each other.

The present study was designed to test this possibility

This research was partially supported by Grants GS 2292 and GS 27340 from the National Science Foundation. Request reprints from Bibb Latané, 404C West 17 th Avenue, Columbus, Ohio 43210. by observing pairs of rats over a much longer interval-namely, $71 / 2 \mathrm{~h}$. In addition, half the pairs were observed after 7 days of social isolation (housed individually) and half after a comparable period of continuous social contact (housed in pairs). If the attraction shown in previous studies were merely a transitory response to the novelty of a new partner, we should expect that all pairs would sooner or later show a decrement in sociability, and that this would occur sooner for pair-housed animals to whom another rat is not uncommon.

\section{METHOD}

\section{Subjects and Apparatus}

Twenty-four male hooded rats, born in the Ohio State colony, had been housed in group cages for about 2 months after weaning. Seven days before the start of the experiment, half were housed individually in single cages and half were housed in pairs, food and water ad lib. On the day of testing, rats were about 90 days old.

Rats were observed in a circular wooden open field, $4 \mathrm{ft}$ in diam with an 18 -in. surrounding wall. Four fields were used simultaneously: three were painted white, two of which were marked with black lines into 49 equal areas, and one was painted black with white lines. Previous research has shown little effect due to the color of the field (Eckman, Meltzer, \& Latané, 1969).

\section{Procedure}

On the day of the experiment, pairs of rats from the same housing condition (but not cagemates) were placed in the open field and allowed to run around freely, to interact, or, of course, to avoid each other for $7 \frac{1 / 2}{2}$ continuous hours. No food or water was available in the open field. The experiment was replicated on 3 separate days, so a total of 12 pairs of rats were observed.

Rats' behavior was observed during thy first $5 \mathrm{~min}$ of testing and thereafter for 155 -min periods, spaced 25 min apart. For three of the four pairs of rats observed on a given day, observers recorded the numbered locations of each rat at 10 -sec intervals. These were later analyzed by computer to provide the activity index described below.

For all pairs of rats, another observer recorded the amount of time spent in direct physical contact. Time in contact was counted whenever the rats touched each other, including vibrissal contact, but excluding only tail-to-tail contact. 


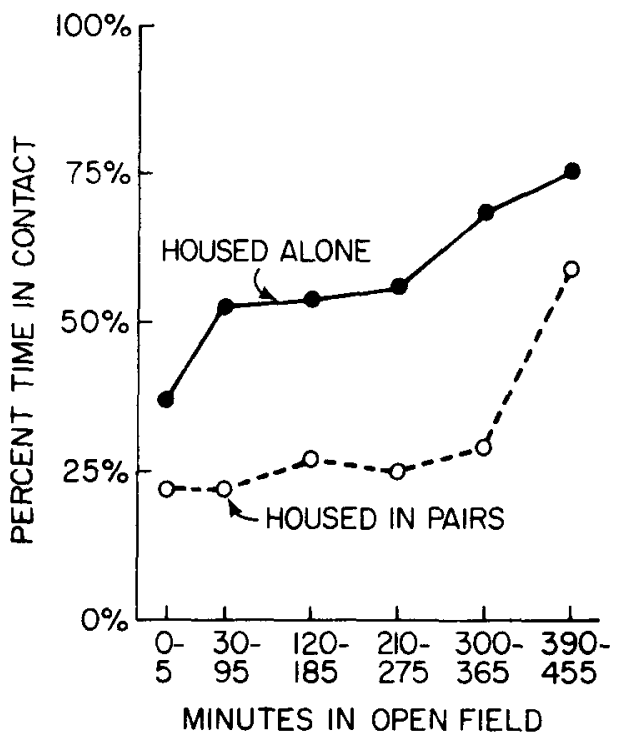

Figure 1. Effects of prior housing on social attraction over $71 / 2$ h of continuous testing ( $N=6$ pairs per condition).

\section{RESULTS}

\section{Affiliation}

Rats were moderately sociable during the first $5 \mathrm{~min}$ of testing, averaging $29 \%$ time in contact. Far from decreasing in affiliation with further contact, they showed a substantial increase in sociability, maintaining about $40 \%$ time in contact over the next $6 \mathrm{~h}$ and rising to $67 \%$ time in contact during the last $1 \frac{1 / 2}{\mathrm{~h}}$ $[F(15,150)=2.10 ; p=.01] .1$ Each of the 12 rat pairs spent more time in contact during the last $1 \frac{1}{2} \mathrm{~h}$ of testing than during the first period.

Rats that were housed alone prior to the experiment spent significantly more time in contact than rats housed in pairs prior to the experiment $(\mathrm{F}=14.6 ; \mathrm{df}=1,10$; $\mathrm{p}<.001)$. During no observational period did the together-housed rats spend more time in contact than the alone-housed rats.

During the first $1 \frac{1}{2} \mathrm{~h}$, animals who had been housed alone showed a much greater increase in attraction $(U=5, p<.05)$ than animals who had been housed in pairs. Similar interactions between housing conditions and exposure to the open field of about this magnitude have been observed in other studies (Latané, Cappell, \& Joy, 1970; Latané \& Walton, 1972) with similar durations of exposure to the field.

Both curves remained relatively flat for the next 4-5 h, when there was another rise, less easy to explain. This latter rise may be related to the dramatic change in behavior that took place over the testing period.

\section{Immobility}

As time went by, rats became much less active in the open field, and the character of their social contact changed. During the first observation period, rats explored the open field, running around it and sniffing the walls. Their social contact primarily consisted of active interaction; chasing each other about and climbing over and under each other. An immobility index, calculated from the number of 10 -sec periods in which rats did not change their locations showed rats were immobile during only $36 \%$ of the intervals in the first observation period.

Immobility rose substantially during the remainder of the test period, averaging $80 \%$ over the next $6 \mathrm{~h}$ and $95 \%$ during the last $1 \frac{1}{2} \mathrm{~h}$. Rats spent a good deal of this time apparently asleep. Social contact often involved huddling together or lying on top of one another, rather than active interaction or play.

\section{Correlations Between Contact and Immobility}

Obviously, over periods, contact and immobility were highly correlated, both increasing monotonically during the $7 \frac{1}{2} \mathrm{~h}$ of observation. The rank order correlation of average contact and immobility per period over the 16 observation periods was $+.78(\mathrm{p}<.01)$. However, this does not give a complete picture of the relationship. The correlations of contact and immobility per rat pair (collapsed over time) over the nine pairs of rats for which immobility data are available is -.47 , nonsignificant, but strikingly different from the positive correlation over periods. Overall, those rats which were most sociable tended to be most active, but sociability increased while activity decreased over time.

Figure 2 shows the average correlation between contact and immobility as it changed over time. Early in the session, the correlation tended to be negative, though not strongly. In only one of the first eight observation periods was a positive correlation obtained.

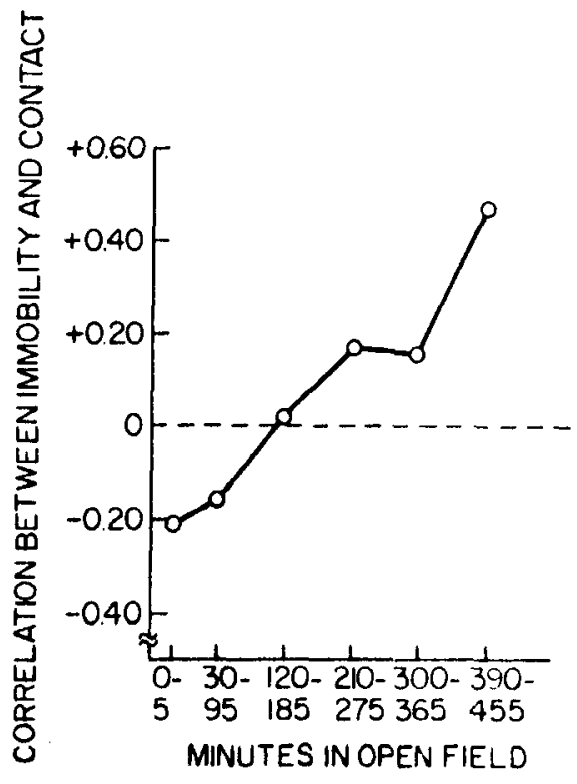

Figure 2. Correlations between immobility and contact as a function of time in the open field. 
During the last half of the session, correlations tended to be positive, being negative in only two of the last eight periods $(p<.05)$. In fact, the correlation between amount of time in the open field and the correlation relating contact and immobility was $+.65(\mathrm{p}<.01)$. Thus, rats changed from predominantly active interaction in which the most sociable animals were most mobile to a predominantly passive huddling in which the most sociable animals were least mobile.

\section{DISCUSSION}

Since food and water were not available in the open field, rats presumably became increasingly hungry and thirsty as time progressed. It is unlikely that hunger had a direct effect on sociability, however, since Latané, Nesbitt, Eckman, and Rodin (1972) report no differences in social attraction between rats tested just before their scheduled feeding on a 23-h deprivation cycle and rats tested just after.

This experiment employed hooded rats as subjects, while most previous research in this series has used albinos. There is no reason, however, to expect that the strains differ either in sociability or in the laws governing their social attraction. Latané, Edwards, Steele, and Walton (1973) tested both types of rat in the same experiment and found little difference in social at traction or in the increase in attraction with continued exposure to the testing arena between the strains, either in within- or cross-strain pairings. The present experiment further supports the generality of such findings in its replication of housing differences and of a Housing by Exposure interaction previously obtained only with albino rats. Albino and hooded rats do differ in visual acuity (Hermann, 1958) and in emotionality, (Wilcock \& Broadhurst, 1967) but these differences do not seem to have a large impact on sociability.

The major finding of this study, that social attraction increased over $7 \frac{1}{2} \mathrm{~h}$ of continuous exposure, indicates that rats' interest in each other is not transitory, but on the contrary is rather long-lived. The changing pattern of correlations reflects a change over time in the character of social contact from a predominantly active interaction to a predominantly passive huddling together. Both forms of contact represent social attraction in a literal sense-animals stayed much closer to each other and spent more time touching than would be expected by chance if they were indifferent to each other or repelled from each other. However, this result suggests that social contact serves several functions for a rat and that rats may have different motives for coming together.

Results from previous research testing rats only $5 \mathrm{~min}$ a day have suggested that rats are attracted to each other, not by each other's sight, smell, feel, or sound (Latané, Joy, Meltzer, Lubell, \& Cappell, 1972; Borden, Walker, \& Latané, 1973) but by the fact that two rats can interact with each other-each providing incompletely predictable stimulation and each being incompletely able to control the other. Similar findings have shown that deprivation of nonsocial stimulation enhances sociability (Sloan \& Latané, 1974) and that rats are strongly attracted to other responsive objects, even a human hand (Werner \& Latané, 1974). These results suggest that social approach in rats may draw upon motives related to curiosity, playfulness, and need for control.

The present results suggest that such motives may soon become satisfied. Rats, initially quite active, become passive after several hours. But yet they were still attracted to each other. Mason (1965) has made the interesting suggestion that primates and perhaps other animals serve as arousal-regulating mechanisms for each other-seeking arousal-increasing play when arousal is low and arousal-reducing clinging and huddling when arousal or fear is high. Although there is evidence that rats show fewer manifestations of distress in the presence of others (Davitz \& Mason, 1955; Latané, 1969; Morrison \& Hill, 1967), there is no reason to believe, in the present experiment, that arousal was higher at the end of the session than at the beginning. Thus, the results seem opposite to what one might expect from Mason's hypothesis.

Other explanations have their own appeal. Perhaps rats, having exhausted themselves in play, found comfort in the blanket-like warmth of each other's bodies or in the pillow-like softness of each other's fur. It is even possible that our rats were exhibiting a process akin to the human heterosexual progression from the excitement of sex to the contentment of love. Our hunch, however, is that it is not a good idea to take such labels and explanations too seriously too soon. One of the great advantages of animal social studies is that they provide a new perspective, free of the language and thought habits we have grown accustomed to using with humans.

\section{REFERENCES}

Borden, R. J., Walker, M. R., \& Latané, B. Ultrasounds and social attraction: Concomitants not determinants. American Psychological Association, 1973.

Cappell, H., \& Latané, B. Effects of alcohol and caffeine on the social and emotional behavior of the rat. Quarterly Journal of Studies on Alcohol, 1969, 30, 345-357.

Davitz, J. R., \& Mason, D. J. Socially facilitated reduction of a fear response in rats. Joumal of Comparative and Physiological Psychology, 1955, 48, 149-151.

Eckman, J., Meltzer, J., \& Latané, B. Gregariousness in rats as a function of familiarity of environment. Journal of Personality and Social Psychology, 1969, 11, 107-114.

Hermann, G. Beitrage zur Physiologie des Rattenauges. Zeitschrift fur Tierpsychologie, 1958, 15, 462-518.

Joy, V.. \& Latané, B. Autonomic arousal and affiliation in rats. Psychonomic Science, 1971, 25, 299-300.

Latane, B., Cappell, H., \& Joy, V. Social deprivation, housing density and gregariousness in rats. Journal of Comparative and Physiological Psychology, 1970, 70, 221-227.

Latané, B., Edwards, J., Steele, C., \& Walton, D. Social attraction among and between albino and hooded rats. Bulletin of the Psychonomic Society, 1973, 2, 20-22.

Latané, B., \& Glass, D. C. Social and nonsocial attraction in rats. Journal of Personality and Social Psychology, 1968, 9. 142-146. 
Latané, B., Joy, V., Meltzer, J., Lubell, G., \& Cappell, H. Stimulus determinants of social attraction in rats. Journal of Comparative and Physiological Psychology, 1972, 79, 13-21.

Latané, B., Nesbitt, P., Eckman, J., \& Rodin, J. Long- and short-term social deprivation and sociability in rats. Journal of Comparative and Physiological Psychology, 1972, 81, 69-75.

Latané, B., Poor, D., \& Sloan, L. Familiarity and attraction to social and nonsocial objects by rats. Psychonomic Science, 1972, 26, 171-172.

Latané, B., Schneider, E., Waring, P., \& Zweigenhaft, R. The specificity of social attraction in rats. Psychonomic Science, $1971,23,28-29$.

Latané, B., \& Walton, D. Effects of social deprivation and familiarity with the environment on social attraction in rats. Psych onomic Science, 1972, 27, 9-11.

Latané, B., \& Werner, Carol. Social and nonsocial sources of attraction in rats. Psychonomic Science, 1971, 24, 147-148.

Mason, W. A. Determinants of social behavior in young chimpanzees. In A. M. Schrier, H. F. Harlow, and F. Stollnitz (Eds.), Behavior of nonhuman primates II Academic Press, 1965. Pp. 335-364.

Morrison, B. J., \& $\mathrm{Hill}$, W. F. Socially facilitated reduction of the fear response in rats raised in groups or in isolation. Journal of Comparative and Physiological Psychology, 1967, 63, 71-76.
Sloan, L, R \& Latané, B Social deprivation and stimulus satiation in rats. Journal of Comparative and Physiological Psychology, 1974, 87, 1148-1156.

Walton, D., \& Latané, B. Visual vs, physical social deprivation and affiliation in rats. Psychonomic Science, 1972, 26, 4-6.

Herner, C. \& Latané, B. Interaction motivates attraction: Rats are fond of fondling. Journal of Personality and Social Psychology, 1974, 29, 328-334.

Wilcock, J., \& Broadhurst, P. L. Strain differences in emotionality: Open-field and conditioned avoidance behavior in the rat, Journal of Comparative and Physiological Psychology, 1967,63, 335-338.

\section{NOTE}

1. All p values are based on two-tailed tests.

(Received for publication June 10, 1974; revision received October $28,1974$. 